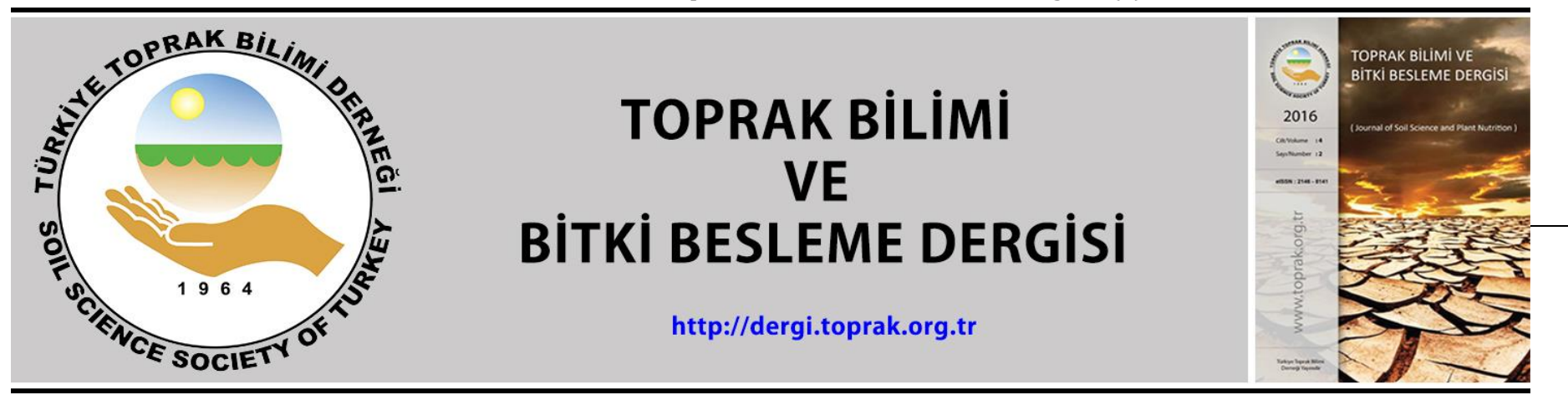

\title{
Toprak sıkışması ve sınırlayıcı su aralığı üzerine farklı organik materyallerin etkileri
}

\author{
• Hamza Negiș, $\odot$ Cevdet Şeker, $\odot$ Ayșe Çetin *
}

Selçuk Üniversitesi, Ziraat Fakültesi, Toprak Bilimi ve Bitki Besleme Bölümü, Konya

\begin{abstract}
Özet
Toprak sıkışması ve buna bağlı toprağın gözenek yapısının değișimi, tarımsal sürdürebilirliği ve bitkisel verimi olumsuz yönde etkilemektedir. Bu olumsuz etkinin azaltılması için çeşitli amenajman uygulamalarının yanında, toprakların organik madde içeriklerinin artırılması önemli bir yer tutmaktadır. Ayrıca son yıllarda, toprak sıkışmasının toprağın fiziksel kalitesine etkisini belirlemede sınırlayıcı su aralığı (SSA) kullanılmaya başlanmıştır. Yapılan bu çalışmada, yüksek sıkışma potansiyeline sahip olan kil tekstürlü bir toprağa, ağırlıkça \%0, 0.5, 1.0, 2.0 ve 4.0 oranlarında sığır gübresi (SG), biyokömür (BK) ve kompost (KO) uygulanmıştır. Uygulama yapılan topraklar altmış günlük inkübasyon çalışması yapılmış, sonrasında standart proktor testine tabi tutulmuştur. Proktor testi ile maksimum düzeyde sıkıștırılan örneklerin hacim ağırlığı (HA), toplam gözenekliliği (TG), tarla kapasitesi (TK), solma noktası (SN), faydalı su kapasitesi (FS) ve SSA üzerine etkileri belirlenmiștir. Buna göre, kontrol (K) örneği ile kıyaslandığında SG, BK ve KO uygulama dozlarındaki artıș ile ters orantılı olarak toprağın maksimum HA değerleri azalmıș ve TG değerleri ise artıș göstermiștir. \%4 SG, BK ve KO uygulama dozlarında HA değerleri kontrole göre sırasıyla; \%12.93, 11.56 ve 14.28 oranında düşerken, TG değerleri de sırasıyla; \% 16.18, 14.38 ve 17.98 oranlarında artmıștır. Ayrıca SSA' nın alt ve üst limitleri uygulamalara bağlı olarak önemli değişkenlikler göstermiş, kullanılan organik materyallerin dozlarındaki artış ile önemli artışlar belirlenmiștir. Sınırlayıcı su aralığında en yüksek artış kompost uygulamasında \%4 dozunda tespit edilmiştir. Buna göre sıkışma eğilimi yüksek ve fiziksel kalitesi düşük olan bir toprağa uygulanan her üç organik materyal de çalışma şartlarında toprağın sıkışma eğilimini azaltarak SSA' yı genişletmiş ve toprağın fiziksel kalitesini iyileştirmiştir.
\end{abstract}

Anahtar Kelimeler: Toprak sıkışması, sınırlayıcı su aralığı, sığır gübresi, biyokömür, kompost.

\section{Effects of different organic materials on soil compaction and least limiting water range}

\begin{abstract}
Soil compaction and its associated change of the pore structure of the soil negatively affect agricultural sustainability and crop yield. In order to reduce this negative effect, it is important to increase soil organic matter content as well as applying various soil management practices. In addition, in the recent years, least limiting water range (LLWR) has been started to be used in the determination of the effect of soil compaction on the soil physical quality. In this conducted study, cattle manure (CM), biochar (BK) and compost (CO) were applied at $0,0.5,1.0,2.0$ and $4.0 \%$ by weight to a clay textured soil with a high compaction potential. Soils treated with amendments were incubated for 60 days and thereafter subjected to standard proctor test. By using the proctor test, the effects of maximum level of compacted samples on bulk density (BD), total porosity (TP), field capacity (FC), wilting point (WP), available water capacity (AWC) and LLWR were determined. Accordingly, when compared with the control (C) sample, the maximum BD values of the soil inversely decreased with the increase in $\mathrm{CM}, \mathrm{BK}$ and $\mathrm{CO}$ application doses while TP values experienced an upward trend. At $4 \%$ of CM, BK and CO application doses, BD values respectively decreased by $12.93 \%, 11.56$ and $14.28 \%$, while TP values respectively increased by $16.18,14.38$ and $17.98 \%$ compared with the control. In addition, the lower and upper limits of LLWR showed significant variations depending on the applications, and significant upward trend, following the increase in the applied doses of the organic materials were demonstrated. The highest increase in least limiting water range was found in the compost applied at 4\%. Accordingly, all three organic materials applied to a soil with a high compaction tendency and low physical expanded SSA and improved soil physical quality through reducing soil compaction tendency in the study area.
\end{abstract}

Keywords: Soil compaction, least limiting water range, cattle manure, biochar, compost.

(C) 2020 Türkiye Toprak Bilimi Derneği. Her Hakkı Saklıdır

\section{Giriş}

Toprak bozulmasının ana nedenlerinden biri, tarım makinelerinin ve hayvan çiğnemesinin neden olduğu sıkıştırmadır (Kunz ve ark., 2013). Tarla trafiğinden kaynaklanan toprak sıkışması birçok önemli toprak

\footnotetext{
* Sorumlu yazar:

Tel. : : 05522031515

E-posta : zmcetinayse@gmail.com
}

Gelis Tarihi

Kabul Tarihi
10 Ağustos 2020

12 Aralık 2020
e-ISSN

DOI
2146-8141

$10.33409 /$ tbbbd.778834 
fonksiyonunu olumsuz yönde etkilemekle birlikte toprağın fiziksel işlevselliğini bozmaktadır. Toprak sıkıșması sonucunda kök büyümesine karşı mekanik direnç artarken, su tutma ve havalanma kapasitesi azalmaktadır (Da Silva ve Kay, 1997; Benjamin ve ark., 2003; Chen ve ark., 2014). Toprak fiziksel özellikleri; bitki büyümesi için su, oksijen ve besin maddelerinin mobilitesi ve alımını doğrudan ve dolaylı olarak etkilemektedir. Su içeriği, hava dolu gözeneklilik, sıcaklık ve penetrasyon direnci gibi toprağın fiziksel özellikleri doğrudan, hacim ağırlı̆̆ı, tekstür, agregat stabilitesi ve gözenek boyutu dağılımı gibi diğer özellikler dolaylı olarak bitki büyümesini etkilemektedir (Letey, 1958). Toprak hacim ağırlığının bitki büyümesi üzerindeki etkisi; su içeriği, havalandırma, kök gelişimi ve büyümesi gibi faktörlerle bağlantılıdır (Da Silva ve Kay, 1997). Sınırlayıcı su aralığı kavramı (SSA); mevcut suyu, toprak havalanmasını ve mekanik direncin kök büyümesinin ciddi bir sınırlama getirdiği noktadaki su içeriği aralığını karakterize eder. Toprakların bulunduğu şartlara göre değişen özelliklerinden; hava dolu gözeneklilik ve tarla kapasitesi değerlerini üst limit olarak, bitki kök gelişiminin yavaşladığı $2 \mathrm{MPa}$ sınır değerindeki nem içeriği ve solma noktası değerlerinin alt limit olarak belirlenmesi ile sınırlayıcı su aralığı belirlenmektedir (Da Silva ve Kay, 1997). Hacim ağırlığı veya penetrasyon direnci gibi tek bir toprak fiziksel özelliği, bitki büyümesi için toprak fiziksel durumundaki değişiklikleri önemli ölçüde açıklanamadığından, çeşitli toprak fiziksel özelliklerinin bir kombinasyonu olan, SSA değişimi, tohumların çimlenmesine ve büyümesine etkisinden dolayı potansiyel bir yaklaşımdır. Artan hacim ağırlığı ve penetrasyon direnci ve azalmış toprak makro gözeneklilik nedeniyle toprağın fiziksel kalitesinin bozulması, bitki büyümesini olumsuz etkileyen SSA' yı azaltır. Genel olarak, SSA ne kadar geniş olursa, bitki büyümesi için toprağın fiziksel kalitesi o kadar iyi olacaktır (Da Silva ve Kay, 1997). Depolanmış kapasitedeki hacimsel su içeriği tarla kapasitesi ile solma noktası arasındaki fark olarak tanımlanırken (Veihmeyer ve Hendrickson, 1950), faydalı su içeriği (FS) de dahil olmak üzere farklı kavramlarla açıklanmaktadır. Sınırlandırılmış su aralığı tanımı Letey (1958) tarafından sadece bitki tarafından temin edilebilen sudan değil aynı zamanda havalandırma ve penetrasyon direncinden de etkilenen sınırlayıcı olmayan su aralığı (NLWR) olarak tanımlanmıştır. Bu kavrama dayanarak Da Silva ve ark. (1994) toprak hacim ağırlığını SSA' ya dahil ederek saha ölçeğinde uygulama için SSA yaklaşımını geliştirmiştir. Sonuç olarak SSA, su potansiyeli, havalandırma ve penetrasyon direnci ile ilişkili bitki büyümesi üzerindeki sınırlamaların minimum olduğu toprak su içeriği aralığı olarak tanımlanmaktadır (Da Silva ve ark., 1994; Tormena ve ark., 1999). Aynı zamanda biyolojik işlemlerin toprak suyu veya oksijen mevcudiyeti ile en az sınırlı olduğu hacimsel toprak suyu içeriğinin minimum aralığıdır (Drury ve ark., 2003). Çok faktörlü bir endeks olarak, SSA birçok fiziksel özelliği tek bir değişkene entegre eder (Da Silva ve ark., 1994) ve farklı yönetim sistemleri altında toprak fiziksel kalitesini değerlendirmek için bir gösterge olarak önerilmiştir (Benjamin ve ark., 2003; Lapen ve ark., 2004). Sinırlandırılmış su aralığı, üç ana bitki büyümesini sınırlayıcı faktörün (penetrasyon direnci, havalandirma ve toprak suyu potansiyeli) tek bir parametreye (Da Silva ve ark., 1994) entegrasyonuna izin verdiği için toprak fiziksel kalitesinin değerlendirilmesi için önemli bir endekstir (Tormena ve ark., 1998; Da Silva ve Kay, 2004).

Daha geniş SSA' ya sahip topraklarda, bitkiler tarafından su alımı daha dar SSA' ya sahip topraklara göre daha kolay olmaktadır (Da Silva ve Kay, 1997). Başarılı yönetim uygulamaları, daha geniş bir SSA' ya yol açarken, dar bir SSA, yönetim uygulamalarının o kadar başarılı olmadığını ve ürün verimliliğinin azalmasına neden olduğunu göstermektedir (Zou ve ark., 2000; Chan ve ark., 2006).

Sınırlandırılmış su aralığı ile ilgili olarak, mevcut araştırmalar yönetim uygulamalarının, toprak yapısı ve toprak sıkışması gibi toprak dinamik özellikleri üzerindeki etkilerini hedeflemektedir (Tormena ve ark., 1999; Zou ve ark., 2000; Dalvan ve ark., 2002; Wu ve ark., 2003; Bulmer ve Simpson, 2005). Toprakların organik madde içeriğinin arttırılmasının genellikle toprak özellikleri üzerinde olumlu bir etkisi olduğu düşünülmektedir (Alaboz ve Öz 2020). Toprak organik maddesi, toprakların toplam gözeneklilik, hacim ağırlığı, gözenek boyutu dağılımı ve mekanik direncinin, kök gelişimi, bitkiye su ve oksijen temini üzerinde büyük etkisi olan yapısal özelliklerdir (Turgut ve Öztaş, 2012; Akpınar, 2018).

$\mathrm{Bu}$ nedenle, bu çalışmanın amacı, kurak ve yarı kurak alanlarda toprak organik maddesindeki değişim ile toprağın sıkıştırılma derecesini azaltmasına bağlı olarak SSA' nın aralığının nasıl değişim gösterdiğini bulmaktır. Bu değişime göre, bitkilerin SSA' nın üst ve alt sınırı arasında daha uzun süre toprak neminden faydalanacağı anlamına gelmektedir. Planlanan çalışmada farklı materyaller kullanılarak organik madde kapsamı arttırılan bir toprağın maksimum sıkışma kapasitesindeki SSA değişimi incelenerek, toprağın fiziksel kalitesine etkileri belirlenmiştir.

\section{Materyal ve Yöntem}

\section{Denemenin Kurulması ve Yönetilmesi}

Sınırlandırılmış su aralığının değişimini incelemek için, Selçuk Üniversitesi Ziraat Fakültesi Sarıcalar Araştırma ve uygulama çiftliğinden, 0-30 cm derinlikten, sıkışma eğilimi yüksek olan yüksek kil içeriğine sahip 
toprak örnekleri alınmıştır. Örnekler laboratuvar şartlarında hava kuru hale getirildikten sonra 4 mm' lik elekten geçirilerek deneme kurulmasına hazır hale getirilmiştir. Denemenin kurulması ve yürütülmesi için toprağın genel fiziksel ve kimyasal analizleri yapılmıştır. Yapılan analizler ve uygulanan metotlar Çizelge 1'de açıklanmıştır.

Çizelge 1. Denemede kullanılan toprağın ve materyallerin bazı fiziksel ve kimyasal özellikleri

\begin{tabular}{lccccr}
\hline Parametreler & Toprak & SG & BK & KO & Metot \\
\hline Kil (\%) & 52.10 & - & - & - & Gee ve Bauder (1986) \\
Silt (\%) & 32.50 & - & - & - & \\
Kum (\%) & 15.40 & - & - & - & Wright ve Bailey (2001) \\
OK (\%) & 1.33 & 43.48 & 49.80 & 20.36 & McLean (1983) \\
$\mathrm{CaCO}_{3}(\%)$ & 23.20 & - & - & - & Gugino ve ark. (2009) \\
pH $\left(\mathrm{H}_{2} \mathrm{O}, 1: 1\right)$ & 7.64 & 7.54 & 8.96 & 8.80 & Blake ve Hartge (1986) \\
$\mathrm{EC}\left(\mathrm{H}_{2} \mathrm{O}, 1: 1, \mu \mathrm{S} \mathrm{cm}^{-1}\right)$ & 748 & 1330 & 184 & 3487 & - \\
$\mathrm{Pk}\left(\mathrm{g} \mathrm{cm}^{-3}\right)$ & 2.65 & - & - & - & Cassel ve Nielsen (1986) \\
TK (\%) & 32.56 & - & - & - & \\
$\mathrm{SN}(\%)$ & 21.60 & - & - & - & \\
FS (\%) & 10.96 & - & - & -
\end{tabular}

SG, sığır gübresi; BK, biyokömür; KO, kompost; $\mathrm{OK}$, organik karbon içeriği; $\mathrm{CaCO}_{3}$, kireç içeriği; EC, elektriki iletkenlik; TK, tarla kapasitesi; SN, solma noktası; FS, faydalı su; Pk, zerre yoğunluğu.

Kullanılan materyallerden sığır gübresi bölgedeki hayvancllık yapan işletmeden temin edilmiş, biyokömür, mısır hasat artığından, $450^{\circ} \mathrm{C}^{\prime}$ de yavaş piroliz yöntemiyle laboratuvar şartlarında üretilmiştir. Kompost ise iğde ağacı budama artığının kompostlaştırılması ile elde edilmiştir. Her 3 materyalin de bazı kimyasal özellikleri Çizelge 1'de verilmiştir.

Deneme toprakları fırın kuru ağırlık esasınca $5 \mathrm{~kg}$ tartılıp saksılara eklenmeden önce materyal karışımları gerçekleștirilmiştir. Her bir materyal (sığır gübresi, biyokömür ve kompost) ağırlıkça \%0, 0.5, 1, 2 ve 4 oranında toprağa ilave edilerek 60 gün süre ile inkübasyona oda koşullarında $\left(23 \pm 3 C^{\circ}\right)$ bırakılmıştır. Organik materyaller topraklara karıștırılmadan önce $4 \mathrm{~mm}$ 'lik elekten elenmiștir. Karıștırılan ve saksılara doldurulan örneklere tarla kapasitesi değerinin \%80'ine gelecek șekilde saf su uygulanmıştır. İnkübasyona bırakılan saksılardan 15 günde bir nem örneklemesi yapılıp ihtiyaç duyulan su (tarla kapasitesinin \%80'i) saksılara hesaplanarak tekrar ilave edilmiştir. Altmış gün sonunda SSA hesaplanması için örneklemeler yapılmıştır.

\section{Maksimum Hacim Ağırlı̆̆ının Belirlenmesi}

İnkübasyon denemesi sonucunda, toprak hacim ağırlığındaki değişimin belirlenmesi için kontrol toprağına proktor testi uygulanmıștır (Mertoğlu, 1982). Test Çizelge 1'de belirlenen tarla kapasitesi ve solma noktası nemleri arasında gerçekleştirilmiştir (\%19.09, 20.69, 23.25, 25.87, 31.00, 34.50, 36.12). Test sonucunda elde edilen verilerden, kontrol toprağının maksimum hacim ağırlığı için gereken nem miktarı \%27.96 ve bu nemdeki maksimum hacim ağırlığı ise $1.47 \mathrm{~g} \mathrm{~cm}^{-3}$ olarak hesaplanmıştır (Şekil 1). Deneme deseni, toprakların maksimum hacim ağırlığına ulaştırılacak nemin belirlenmesi ile uygulama yapılan topraklar yaklaşık ağırlık esasına göre \%27 nem kapsamına getirilerek standart proktor sıkıştırma testi uygulanmıştır. Uygulanan proktor testi sonucunda deneme topraklarının maksimum hacim ağırlıkları hesaplanmıştır (Çizelge 2).

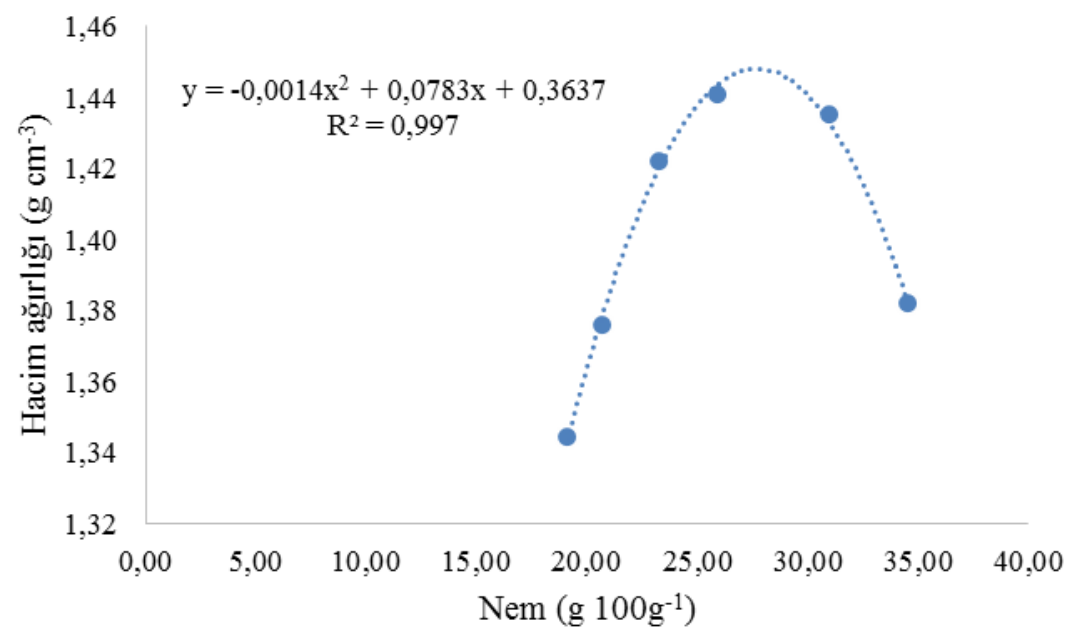

Şekil 1. Kontrol toprağının proktor testi sonucu 


\begin{tabular}{lccc}
\hline \multicolumn{2}{l}{ Cizelge 2. Topraklarının maksimum hacim ağırlı̆̆ ve porozitesinde ki değişimler } \\
\hline Örnek & Doz $\mathbf{~ \% )}$ & HA $\left(\mathbf{g ~ c m}^{-3}\right)$ & P \\
\hline K & 0 & $1.47 \pm 0.02^{\mathrm{a}}$ & $0.445 \pm 0.004^{\mathrm{h}}$ \\
& 0.5 & $1.36 \pm 0.01^{\mathrm{d}}$ & $0.487 \pm 0.004^{\mathrm{e}}$ \\
SG & 1 & $1.35 \pm 0.02^{\mathrm{d}}$ & $0.491 \pm 0.004^{\mathrm{e}}$ \\
& 2 & $1.34 \pm 0.01^{\mathrm{de}}$ & $0.496 \pm 0.002^{\mathrm{de}}$ \\
& 4 & $1.28 \pm 0.00^{\mathrm{gh}}$ & $0.517 \pm 0.004^{\mathrm{ab}}$ \\
BK & 0.5 & $1.44 \pm 0.01^{\mathrm{b}}$ & $0.457 \pm 0.003^{\mathrm{g}}$ \\
& 1 & $1.40 \pm 0.02^{\mathrm{c}}$ & $0.472 \pm 0.002^{\mathrm{f}}$ \\
& 2 & $1.34 \pm 0.03^{\mathrm{de}}$ & $0.494 \pm 0.001^{\mathrm{de}}$ \\
KO & 4 & $1.30 \pm 0.01^{\mathrm{fg}}$ & $0.509 \pm 0.000^{\mathrm{bc}}$ \\
& 0.5 & $1.35 \pm 0.00^{\mathrm{d}}$ & $0.491 \pm 0.002^{\mathrm{e}}$ \\
& 1 & $1.34 \pm 0.03^{\mathrm{de}}$ & $0.494 \pm 0.004^{\mathrm{de}}$ \\
& 2 & $1.32 \pm 0.00^{\mathrm{ef}}$ & $0.502 \pm 0.001^{\mathrm{cd}}$ \\
\hline
\end{tabular}

K: Kontrol; SG: Sığır gübresi; BK: Biyokömür; KO: Kompost; HA: Hacim ağırlığı, P: Porozite

\section{Sınırlandırılmış Su İçeriğinin Belirlenmesi}

Sınırlandırılmış su aralığının karakterizasyonu için üst ve alt limitlerin belirlenmesi gerekmektedir. Üst limitler $-33 \mathrm{kPa}$ ' daki (tarla kapasitesi) toprak suyu içeriği ve porozitenin \% 10 eksiğine karşllık gelen hava dolu gözeneklilik (Grable ve Siemer, 1968), alt limitler ise $-1500 \mathrm{kPa}$ daki (solma noktası) ve $2 \mathrm{MPa}$ penetrasyon direncine eşdeğer toprak suyu içeriğidir (Taylor ve ark., 1966). Her bir uygulama yapılan toprakta 2 farklı su tutma ölçümüne karşılık gelen (-33 ve $-1500 \mathrm{kPa})$ basınçlarda, basınç plakası aygıtı kullanılarak ölçümleri gerçekleştirilmiştir. Basınç plakasına konulmadan önce örnekler 24 saat boyunca yavaşça doyurulmuşlardır. Basınç plakasındaki örneklerde su çıkışının durduğu zaman (yaklaşık 48-72 saat) örnekler çıkarılmıştır. Yaş ağırlık (YA) tartımı yapılan örnekler, $105{ }^{\circ} \mathrm{C}$ ' deki etüve konularak sabit ağırlığa gelene kadar (24 saat) bekletilmiştir. Etüvden çıkarılan örneklerde tekrar tartım yapılıp fırın kuru ağırlıkları (KA) belirlenmiştir. -33 ve -1500 kPa basınç altında tutulan su içerikleri belirlenmiştir. Ayrıca her bir toprak örneği için SSA'nın belirlenmesinde, toprakların alt ve üst limitlerindeki değişimler göz önüne alınmış ve denklemlerden uygun olan seçilerek hesaplanmıştır (Eşitlik 1, 2, 3 ve 4).

$$
\begin{array}{cc}
\left(\theta_{\mathrm{HDG}} \geq \theta_{\mathrm{TK}}\right) \text { ve }\left(\theta_{\mathrm{PD}} \leq \theta_{\mathrm{SN}}\right) ; & S S A=\theta_{T K}-\theta_{S N} \\
\left(\theta_{\mathrm{HDG}} \geq \theta_{\mathrm{TK}}\right) \text { ve }\left(\theta_{\mathrm{PD}} \geq \theta_{\mathrm{SN}}\right) ; & S S A=\theta_{T K}-\theta_{P D} \\
\left(\theta_{\mathrm{HDG}} \leq \theta_{\mathrm{TK}}\right) \text { ve }\left(\theta_{\mathrm{PD}} \leq \theta_{\mathrm{SN}}\right) ; & S S A=\theta_{H D G}-\theta_{S N} \\
\left(\theta_{\mathrm{HDG}} \leq \theta_{\mathrm{TK}}\right) \text { ve }\left(\theta_{\mathrm{PD}} \geq \theta_{\mathrm{SN}}\right) ; & S S A=\theta_{H D G}-\theta_{P D}
\end{array}
$$

$\theta_{\text {HDG }} \quad$ : Hava dolu gözenekliliğin \%10 olduğu nem içeriği

$\theta_{\text {Тк }} \quad$ : Tarla kapasitesi

$\theta_{\mathrm{SN}} \quad$ : Solma noktası

$\theta_{\mathrm{PD}} \quad$ : Penetrasyon direnci $2 \mathrm{MPa}$ olduğunda toprağın su içeriği

Penetrasyon direncinin 2 MPa' lık kritik bir değere ulaştığı su içeriği, daha önce benzer özelliklere sahip bir toprakta yapılmış olan penetrasyon direnci modeli (Eşitlik 5) kullanılarak hesaplanmıştır (Çetin, 2018):

$$
\theta_{P D}=a * \theta^{b} * P b^{c}
$$

$\theta_{\mathrm{PD}} \quad$ : Penetrasyon direncinin $2 \mathrm{MPa}$ olduğundaki toprak su içeriği $\left(\mathrm{m}^{3} \mathrm{~m}^{-3}\right)$

$$
\begin{array}{ll}
\mathrm{a} & =0.0407 \\
\mathrm{~b} & =-1,8087 \\
\mathrm{c} & =7,8695 \\
\theta & =\text { hacimsel su içeriği }\left(\mathrm{m}^{3} \mathrm{~m}^{-3}\right) \\
\mathrm{P}_{\mathrm{b}} & : \text { Hacim ağırlığı }\left(\mathrm{g} \mathrm{cm}^{-3}\right)
\end{array}
$$

Hava dolu gözenekliliğin \%10'a eşit olduğu su içeriği eşitlik 6 kullanılarak hesaplanmıştır.

$$
\theta_{H D G}=\theta_{s}-0.1
$$

$\theta_{s}$ : toprağın doygunluk düzeyi ( $\%$ )

Üst sınır için tarla kapasitesindeki su içeriği ile hava dolu gözeneklilik arasındaki en düşük değer baz alınmıştır. Alt sınır için ise solma noktasındaki su içeriği ile 2 MPa penetrasyon direncindeki su içeriğinin arasındaki en yüksek değer seçilerek belirlenmiştir.

\section{İstatistiksel analizler}

Deneme tesadüf parselleri deneme planında 3 tekerrürlü olarak yürütülmüştür. Uygulamalar arasındaki önemli farklılıkları test etmek için varyans analizi kullanılmıştır. Ortalamalar 0.05 olasılık düzeyinde Tukey çoklu karşılaştırma testi kullanılarak karşılaştırılmıştır. Tüm veri analizlerinde SPSS istatistik yazılımı kullanılmıştır. 


\section{Bulgular ve Tartışma}

Maksimum sıkıştırma sonucunda kontrol toprağına göre uygulamaların doz oranı arttıkça hacim ağırlığı değerinde düşüş meydana gelmiştir (Çizelge 2). En yüksek hacim ağırlığı değeri $1.47 \mathrm{~g} \mathrm{~cm}^{-3}$ ile kontrol toprağında ölçümü yapılmışken, bu değer uygulamaların en yüksek dozlarında yaklaşık \%13 oranında azalmış, ortalama $1.28 \mathrm{~g} \mathrm{~cm}^{-3}$ olarak hesaplanmıştır. Bu düşüş uygulamaların $\% 0.5,1$ ve 2 dozlarında sırasıyla \%6.12, 7.48 ve 9.52 olarak hesaplanmıştır. Köklerin büyümesi, su ve besin elementi alımı veya verimi kısıtlaması dikkate alındığında hacim ağırlığındaki, bu düşme var olan kısıtlamaların azaltılabileceğinin bir göstergesidir. Toprakların maksimum hacim ağırlı̆̆ değeri ile organik karbon arasındaki ilişkiyi birçok araştırmacı incelemiş, bunlara göre toprakların organik karbon içeriklerindeki artışın hacim ağırlığı değerinin azaldığını, organik karbon içeriğindeki \% 1' lik artışın sıkışmanın yoğun olduğu orta tekstürlü topraklar üzerinde en büyük etkiyi oluşturduğunu göstermişlerdir (Hakansson, 1990; Da Silva ve Kay, 1997).

Deneme toprağının tarla kapasitesi değeri \%33.80 bulunmuş olup, uygulamaların dozlarındaki artışa bağlı olarak tarla kapasitesi değeri de artmış ve istatistiki olarak önemli farklılık ortaya çıkmıştır ( $\mathrm{p}<0.05)$. Organik materyallerin en düşük dozda uygulandığı örneklerde bu artışın düşük olduğu ve istatistiki olarak kontrol ile aynı grupta yer aldıkları görülmektedir (Şekil 2). Doz artışına bağlı olarak tarla kapasitesi değerinin arttığı en yüksek değere en yüksek doz olan \%4' lük uygulamalarda ulaştığı görülmektedir. Sığır gübresi, biyokömür ve kompostun \%4' lük uygulamaları kontrole göre tarla kapasitesi değerlerinde sırasıyla \%6.95, 7.54 ve 8.81 oranlarında artışlar sağlamıştır. Bu artışlar incelendiğinde kompost materyalinin en yüksek oranda artış gösterdiği görülmektedir. Bu durum kompost materyalinin şişme-büzülme miktarındaki fazlalıktan kaynaklandığı düşünülmektedir.

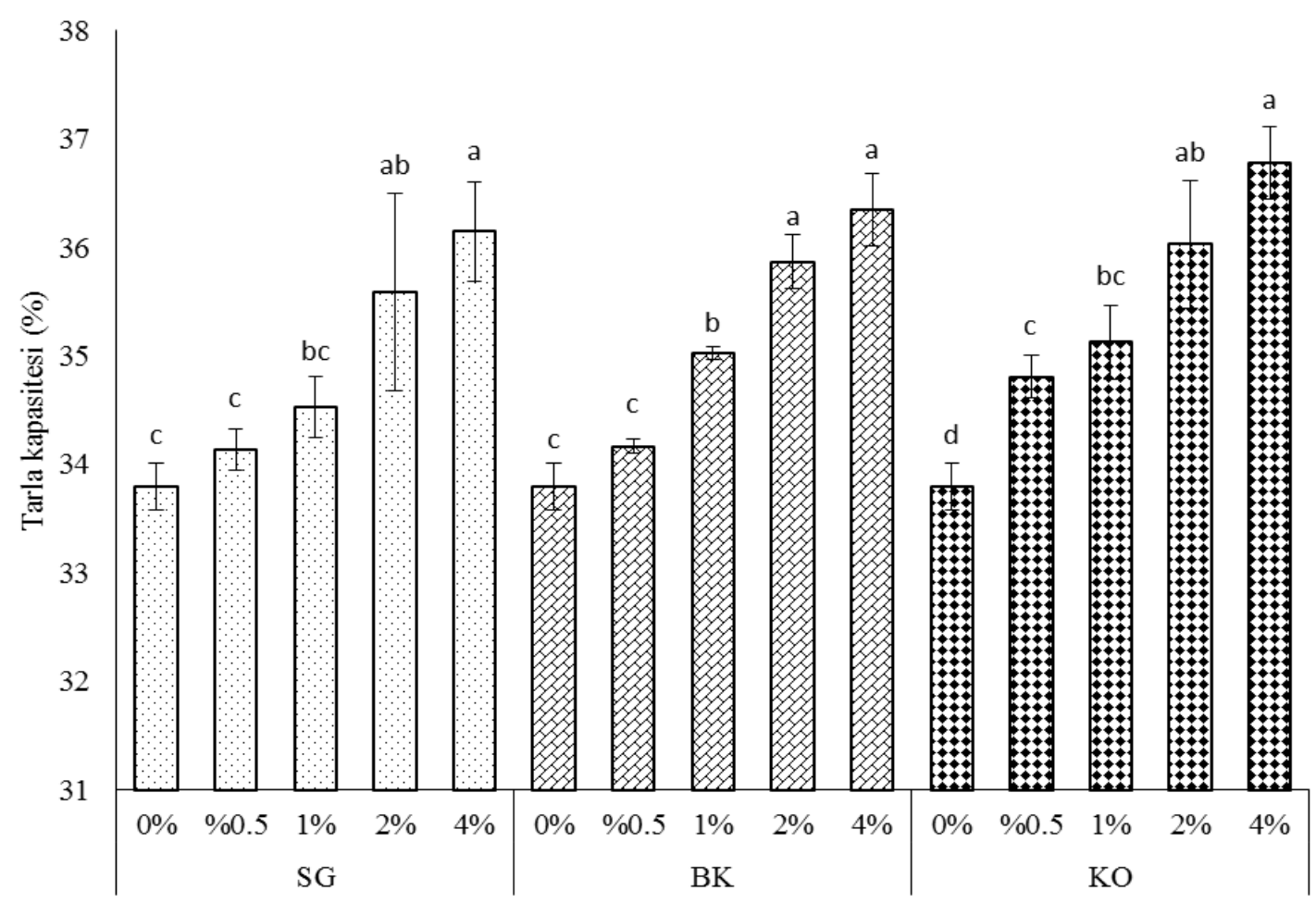

Şekil 2. İnkübasyon sonucunda tarla kapasitesindeki değişimler.

SG: Sığır gübresi; BK: Biyokömür; KO: Kompost.

Solma noktası değerleri incelendiğinde ise kontrol toprağında \%21.63 ölçülmüş iken bu değer uygulanan materyallerin doz oranı arttıkça azalış sergilemiştir. Azalma oranları kullanılan materyallerin kendi içindeki doz artışı ile yaklaşık benzer oranlarda negatif ilişkiler göstermiş, kullanılan materyallerin aynı uygulama dozları arasındaki farklılıklar istatistiksel olarak önemli olmamıştır (Şekil 3). En yüksek düşüş bütün uygulamaların \%4' lük dozunda gerçekleşirken, kompost uygulamasından, biyokömür ve sığır gübresine göre daha düşük değer elde etmiştir. 


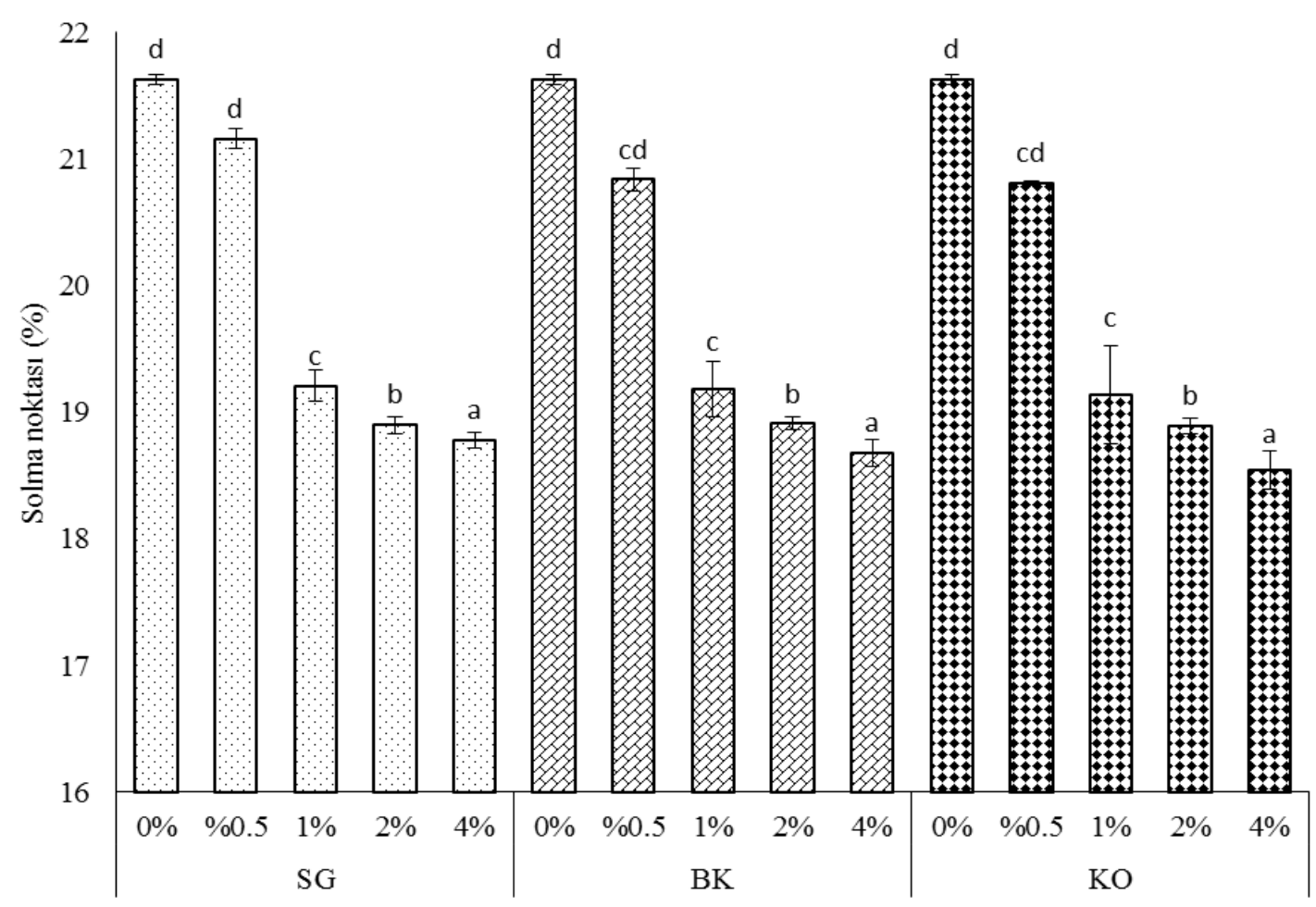

Şekil 3. İnkübasyon sonucunda solma noktasındaki değişimler. SG: Sığıır gübresi; BK: Biyokömür; KO: Kompost.

Tarla kapasitesindeki artış ve solma noktasındaki düşüş faydalı su içeriğinin artmasına neden olmuştur. Bu artış ise bitkilerin daha fazla su kullanım potansiyeline sahip olduğunun bir göstergesidir. Faydalı su değerleri incelendiğinde kontrol toprağının faydalı su içeriği \%12.17 olarak bulunurken, bu değer uygulamaların en yüksek dozunda ortalama \%45.93 oranında artarak \%17.76 olarak hesaplanmıştır (Şekil 4).

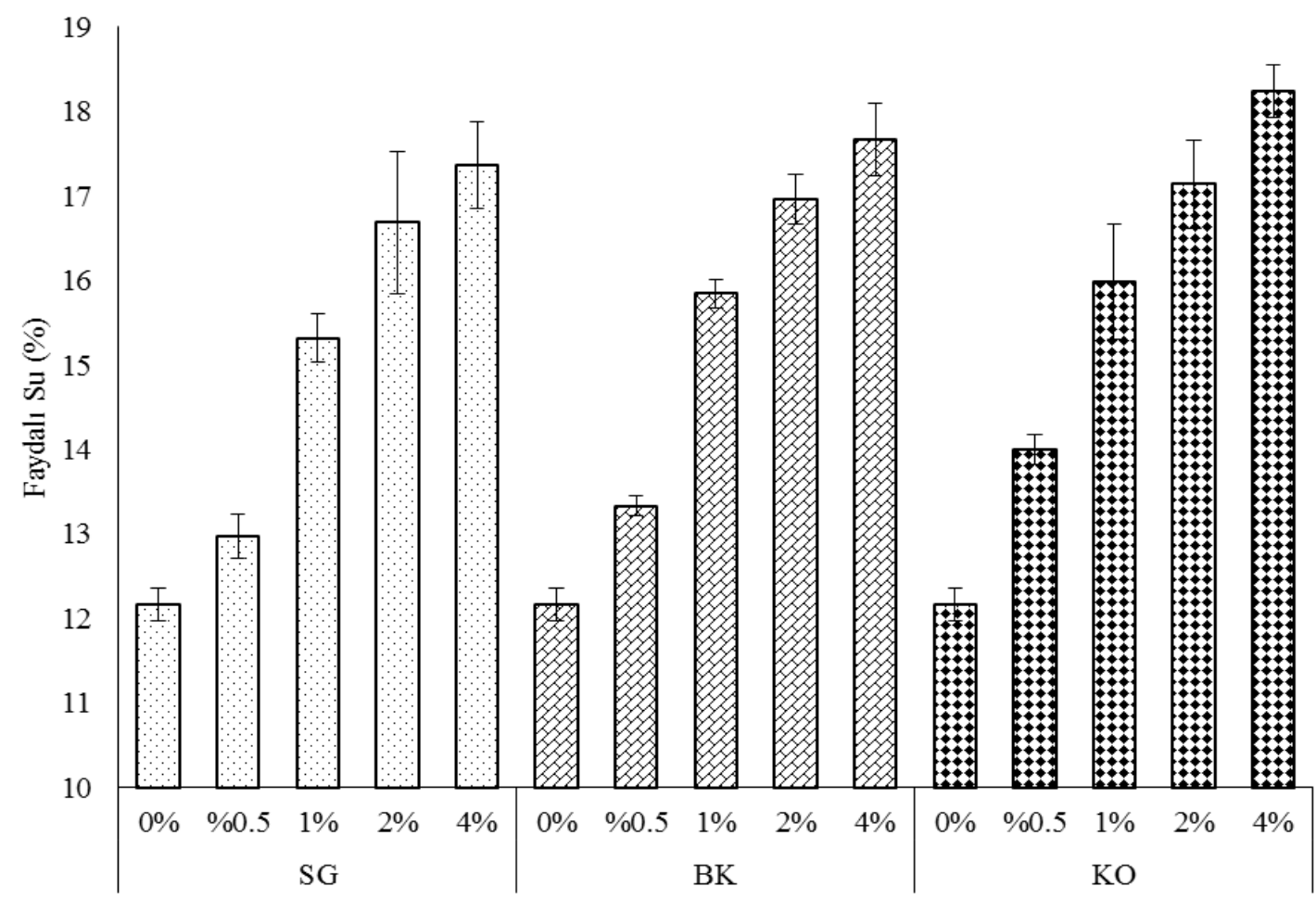

Şekil 4. İnkübasyon sonucunda faydalı su içeriğindeki değişim SG: Sığır gübresi; BK: Biyokömür; KO: Kompost. 
Sınırlandırılmış su aralığının alt ve üst limitlerini oluşturan tarla kapasitesi ve solma noktasındaki bu değişimler bitkilerin faydalanabileceği su miktarı hakkında bize bilgi vermektedir. Ancak bitkilerin yararlanabileceği su içeriği sadece bu iki faktör tarafından etkilenmemektedir. Toprak sıkışması, penetrasyon direnci ve hacim ağırlığl, bitkilerin su alım potansiyelini etkilediği bilinmektedir (Da Silva ve Kay, 1997). Bu nedenden dolayı bitkiler için gelişme bozukluğunun başlangıcı olan 2 MPa sıkışma durumundaki toprak su içeriği önemli bir noktayı oluşturmaktadır. Bitki $2 \mathrm{MPa}$ ve üstü toprak sıkışması durumunda kök gelişimi bundan etkileneceğinden, bitkilerin su ve besin elementi sağladıkları toprak miktar sınırlanacaktır. Ayrıca SSA' nın üst kısmını oluşturan ve yeterli bitki büyümesi için makro gözeneklilik sınırı olan hava dolu gözeneklilik değeri de yeterli su-hava dengesinin oluşması için önemlidir (Baver, 1949; Vomocil ve Flocker, 1961; Grable ve Siemer, 1968; Reichert ve ark., 2009).

Yukarıda ifade edilen durumu daha iyi açıklama için uygulamaların SSA' nın değişimine etkilerini gösteren Şekil 5 oluşturulmuştur. Her bir uygulamanın kontrol toprağına göre karşılaştırılması yapılmış ve aralarındaki farklar ortaya konulmuştur.

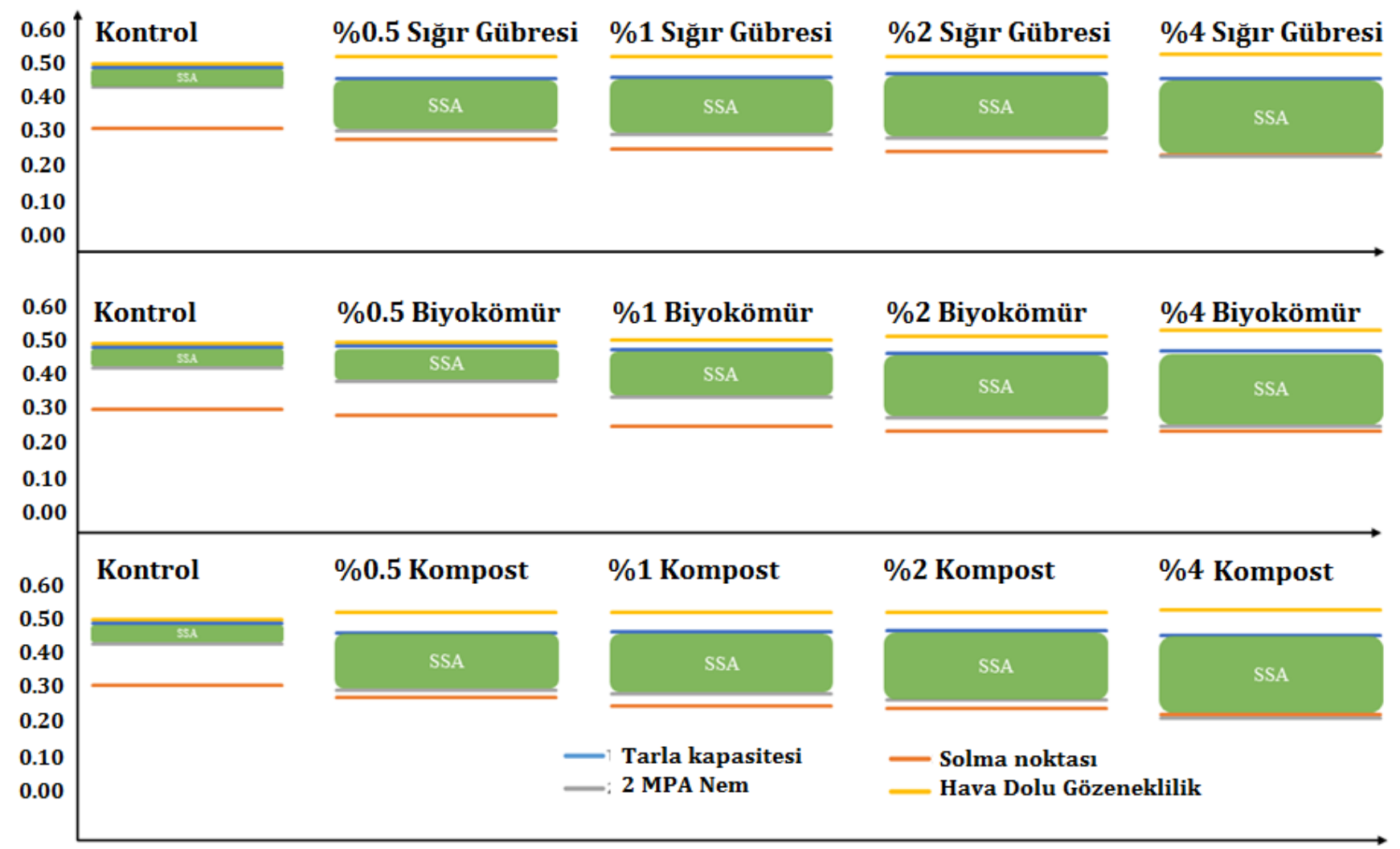

Şekil 5. Sığır gübresi, biyokömür ve kompost uygulamalarının maksimum hacim ağılığında SSA' nın değişimine etkisi

Sınırlandırılmış su aralığı için kontrol toprağı incelendiğinde 2 MPa' daki nem içeriği solma noktasının çok üzerinde olduğu görülmektedir. Hacim ağırlığına bağlı olarak artan toprak sıkışması hem tarla kapasitesinde ve hem de solma noktasında toprakta suyun tutulmasını artırabilir, bu durum makro boyutlu gözeneklerin azalmasına bağlı olarak orta ve mikro boyutlu gözeneklerin artması ile toprakta daha fazla su tutulmasını sağladığını göstermektedir (Hill, 1990; Zou ve ark., 2000; Safadoust ve ark., 2014). Ancak, toprak su içeriği solma noktasına gelmeden bitkinin mevcut sıkışmadan dolayı kök gelişiminin engelleneceği öngörülmektedir. Ayrıca hava dolu gözeneklilik ile tarla kapasitesi değerlerinin de birbirlerine yakın olduğu bulunmuştur. Günümüzde topraklar uygulanan mekaniksel kuvvetlerin artması, tohum yatağı hazırlamadaki yanlışlar, uygun olmayan nemlerde toprak işleme ve dönem içerisinde arazilerin birden çok işlem görmesi nedeniyle toprak sıkışmasındaki artış birçok araștırmaya konu olmuştur (Guedes Filho ve ark., 2013; De Lima ve ark., 2020). Özetle bitki köklerinin havalanması ve gelişimini sınırlamada, toprakların faydalı su içeriklerini artıracak uygulamaların bitkilerin gelişimi ve verim potansiyellerine yükselmesini sağlayabilecektir. Aksi durumda kurak bölgelerde bitkilerin su kullanım etkinliği, nemli bölgelerde ise havalanma yetersizliği nedeniyle bitki gelişimi olumsuz etkilenebilecektir. Çalıșmada, uygulamaların \%0.5' lik dozları incelendiğinde biyokömürün diğer iki materyale kıyasla daha az etkili olduğu görülmektedir. Bu durum \%1 ve \%2' lik uygulama dozlarında da benzer şekilde çıkmıştır (Şekil 5). 
Diğer taraftan, Şekil 5 incelendiğinde kontrole göre SSA miktarı önemli ölçüde artmıştır. Her ne kadar sığır gübresi veya kompost kadar fark sağlayamamış olsa da kontrol toprağına göre biyokömür uygulaması bitki köklerinin havalanması ile kök gelişimine uygun ortam hazırlaması bakımından fark yaratmıștır. Biyokömürün diğerlerine göre daha az artış oluşturması onun daha çok fiziksel yapısı ile ilgili olduğu değerlendirilmektedir. Biyokömürün çoğu çeşitlerinde gözeneklerin büyük bir kısmının 0.002 mm çaptan daha az olduğunu yapılan çalışmalarca belirlenmiştir (Major ve ark., 2009). Her üç uygulamanın \%4'lük dozları incelendiğinde ise maksimum sıkışma şartlarında bile toprak yapısındaki gevşek yapıyı kaybetmedikleri bulunmuştur. Bitkiler için SSA' nın geniş bir aralıkta yer aldığı görülmektedir, ayrıca her üç uygulamada $2 \mathrm{MPa}$ ' lık sıkışmanın oluştuğu nem içeriği değerleri neredeyse solma noktası değerine yakın çıkmıştır (Şekil 5). Buda uygulamaların sıkışma problemin de azaltıcı rol oynadığının ve bununla birlikte bitkilerin toprakta tutulan sudan daha fazla yararlanacağının bir göstergesidir. Toprak sıkışmasının neden olduğu kök sisteminin konfigürasyonundaki değişiklikler ve sıkışmaya bağlı olarak su ve hava dengesinin bozulması, bitkiler tarafından besin alınımını azaltmasının yanında çevreye de olumsuz etkiler yapmaktadır (Reichert ve ark., 2009). Topraklarda organik maddenin de yetersiz olmasıyla birlikte toprak sıkışması, agregatlardaki gözeneklerinin tahrip edilmesine, havalanma ve su sızıntısının azalmasına, toprağın mukavemetinin artmasına, gözenek fonksiyonlarının kötüleşmesine ve kök gelişiminin azalmasına neden olmaktadır (Horn ve ark., 1995; Lipiec ve Hatano, 2003; Dexter, 2004; Lipiec ve ark., 2012). Bunların bir sonucu olarak, toprak erozyonuna neden olabilecek daha belirgin bir yatay su akışına neden olabilmektedir (Horn, 2004). Sınırlandırılmış su aralığının üst sınırı olan havalanma gözenekliliği ve organik karbon içeriği arasında anlamlı pozitif ilişkiler olduğundan ve artan organik karbon içeriğine bağlı olarak azalan hacim ağırlığının etkisi ile topraklardaki kullanılabilir su içeriği artmıştır (Da Silva ve ark., 1994; Zou ve ark., 2000). Toprak özelliklerindeki değişimlere göre SSA' nın üst sınırları ve alt sınırlarındaki farklılıklar bitkilerin topraktan yararlanabileceği su içeriğini etkilemektedir ve Çizelge 3'te gösterilmiştir. Kontrol toprağında SSA 0.059 olarak ölçülürken \%4 KO uygulama dozunda bu fark yaklaşık \%290 oranında artarak 0.23 hesaplanmıştır. En yüksek artış kompost uygulamasında görülürken bunu sığır gübresi ve biyokömür takip etmiştir. Biyokömür materyalinin mikro gözenekli yapısından dolayı su tutma potansiyelinde farklılıklar görülmektedir (Gray ve ark., 2014; Weber ve Quicker, 2018). Biyokömür karışımının \%0.5 ve 1 dozları incelendiğinde sığır gübresi ve kompost kadar etkili olmadığı görülmektedir.

Çizelge 3. Deneme topraklarının SSA değişimleri

\begin{tabular}{ccl}
\hline Örnek & Doz $(\%)$ & SSA \\
\hline K & 0 & $0.059 \pm 0.02^{\mathrm{m}}$ \\
& 0.5 & $0.153 \pm 0.01^{\mathrm{j}}$ \\
SG & 1 & $0.164 \pm 0.02^{1}$ \\
& 2 & $0.185 \pm 0.01^{\mathrm{f}}$ \\
& 4 & $0.222 \pm 0.00^{\mathrm{b}}$ \\
BK & 0.5 & $0.100 \pm 0.01^{\mathrm{l}}$ \\
& 1 & $0.137 \pm 0.02^{\mathrm{k}}$ \\
& 2 & $0.189 \pm 0.03^{\mathrm{e}}$ \\
KO & 4 & $0.216 \pm 0.01^{\mathrm{c}}$ \\
& 0.5 & $0.168 \pm 0.00^{\mathrm{h}}$ \\
& 1 & $0.180 \pm 0.03^{\mathrm{g}}$ \\
\hline
\end{tabular}

K: Kontrol; SG: Sığır gübresi; BK: Biyokömür; KO: Kompost; SSA: Sınırlayıcı su aralığı

Toprakların SSA değerleri toprak işleme, tarla trafiği, ıslanma-kuruma, donma-çözünme olaylarına ve organik karbon miktarının değişimine bağlı olarak farklılık göstermektedir (Kay ve ark., 1997). Kay ve ark. (2006) tarafından yapılan çalışmada SSA' nın değişim oranı, toprakların kararlılık ve esneklik özelliklerinin bir fonksiyonu olduğu ve bu özelliklerin de organik karbon içeriklerinden etkilenmesi ile meydana geldiği bildirilmiştir. Bununla birlikte, bugüne kadar yapılan çalışmalarda SSA' nın değişim oranlarının kararlılık veya esneklikteki değişikliklere cevaben nicel tahminlerine izin veren hiçbir fonksiyonel ilişki kurulmamıştır. Sonuç olarak, organik karbon içeriklerindeki değişikliklerin zaman içinde SSA' daki değişiklik üzerindeki etkisi değerlendirilmemiştir (Kay ve ark., 1997). Bu çalışma verileri göstermektedir ki organik karbon miktarındaki artışa bağlı olarak topraklardaki sıkışmanın azalması, bitkilerin gelişebileceği SSA limitlerini arttırmıştır. Topraklardaki organik karbon miktarındaki değişim ile plastik özellikleri artacağından toprak hacim ağırlığında azalma ve ilave edilen materyallerin boşluk oranlarındaki farklılıklar ve yüzey alanındaki değișimler ile toprakların su tutma potansiyeli etkilenmektedir (Yang ve Lu 2020). 


\section{Sonuç}

Bitkisel üretimde, tohum ekiminden sonra çimlenme ve filiz çıkışından hasada kadar olan dönemde kök gelişimine uygun bir ortam hazırlanması verim ve kaliteyi önemli ölçüde etkilemektedir. Ayrıca toprakların suyu depolayabileceği gözenek yapısının geliştirilmesi özellikle kurak ve yarı kurak alanlarda üretimin sürdürülebilirliğine önemli katkılar oluşturmaktadır. Yapılan çalışmada kullanılan her üç organik materyal de bitkilerin kullanımına uygun faydalı su içeriğini artırmada, doz artışı ile artan şekilde, benzer olumlu etki gösterilmiştir. Bu nedenle her üç materyalin de ekonomikliği dikkate alınarak faydalı su içeriğini artırmada kullanılabileceği görülmüştür. Toprak sıkışmasının azaltması ve havalanma gözenekliliğini artırılması ile SSA' nın genişletilmesi bakımından her üç organik materyal de etkili olmakla birlikte, en etkin materyalinin kompost olduğu, bunu sığır gübresi ve biyokömür uygulamalarının takip ettiği görülmektedir. Uygulamalar arasındaki bu farklılıkların yüzey alanlarındaki farklılıklardan meydana geldiği öngörülmektedir. Bu artışların daha fazla SSA' nın alt limitinde, $2 \mathrm{MPa}$ su içeriğinde, meydana geldiği tespit edilmiştir. Yönetim uygulamalarıyla birlikte artan sıkışmanın su kullanımını etkilediği ve SSA' yı daralttığı topraklarda, kompost, sığır gübresi ve biyokömür gibi materyallerin kullanımı gerek bitki gelişimi ve gerekse tarımsal sürdürülebilirliğin sağlanması üzerinde büyük etkiye sahip olacaktır. Genel anlamda su sıkıntısı yaşayan bölgemiz topraklarında kompost, sığır gübresi ve biyokömür gibi organik karbon miktarını arttırıcı uygulamaların teşvik edilmesinin gerekliliği bir kez daha faklı boyutta ortaya konmuştur.

\section{Kaynaklar}

Akpınar Ç, 2018, Farklı Organik Gübre Uygulamalarının Mısır Bitkisinin Gelişimi ve Besin Elementleri Alımına Etkileri. Alatarım, 33.

Alaboz P, Öz H, 2020. Biyokömür ve Solarizasyon Uygulamalarının Bazı Toprak Fiziksel Özellikler Üzerine Etkileri., Anadolu Tarım Bilimleri Dergisi, 35 (2), 208-214.

Baver L, 1949. Practical values from physical analyses of soils. Soil science. 68 (1): 1-14.

Benjamin J, Nielsen D, Vigil M, 2003. Quantifying effects of soil conditions on plant growth and crop production. Geoderma. 116 (1-2): 137-148.

Blake G R, Hartge K, 1986. Bulk density. Methods of soil analysis: Part 1 Physical and mineralogical methods. vol. 5. pp.363-375.

Bulmer C, Simpson D, 2005. Soil compaction and water content as factors affecting the growth of lodgepole pine seedlings on sandy clay loam soil. Canadian Journal of Soil Science, 85 (5): 667-679.

Cassel D, Nielsen D, 1986. Field capacity and available water capacity. Methods of soil analysis: Part 1 Physical and mineralogical methods. vol. 5. pp. 901-926.

Chan K, Oates A, Swan A, Hayes R, Dear B, Peoples M, 2006. Agronomic consequences of tractor wheel compaction on a clay soil. Soil and Tillage Research. 89 (1): 13-21.

Chen G, Weil R R, Hill R L, 2014. Effects of compaction and cover crops on soil least limiting water range and air permeability. Soil and Tillage Research 136: 61-69.

Çetin A, 2018. Toprak nemi ve hacim ağırlığının penetrasyon direncine etkisi. Yüksek Lisans Tezi Selçuk Üniversitesi Fen Bilimleri Enstitüsü, Konya.

Da Silva A, Kay B, Perfect E, 1994. Characterization of the least limiting water range of soils. Soil Science Society of America Journal. 58 (6): 1775-1781.

Da Silva A P, Kay B, 1997. Effect of soil water content variation on the least limiting water range. Soil Science Society of America Journal. 61 (3): 884-888.

Da Silva A P, Kay B, 2004. Linking process capability analysis and least limiting water range for assessing soil physical quality. Soil and Tillage Research. 79 (2): 167-174.

Dalvan R, Richard W, Birl L, Francisco A, 2002. Compaction effects on least limiting water range and plant growth. 17. World congress of soil science, 14-21 August, Bangkok (Thailand),

De Lima R P, Keller T, Giarola N B, Tormena C A, Da Silva A R, Rolim M M, 2020. Measurements and simulations of compaction effects on the least limiting water range of a no-till Oxisol. Soil Research. 58 (1): 62-72.

Dexter A R, 2004. Soil physical quality: Part I. Theory, effects of soil texture, density, and organic matter, and effects on root growth, Geoderma, 120 (3-4), 201-214.

Drury C, Zhang T, Kay B, 2003. The non-limiting and least limiting water ranges for soil nitrogen mineralization. Soil Science Society of America Journal. 67 (5): 1388-1404.

Gee G, Bauder J, 1986. Particle-size analysis. In A. Klute (ed.) Methods of soil analysis. Part 1. Agron. Monogr. 9. ASA and SSSA, Madison, WI, Particle-size analysis. . pp. 383-411.

Grable A R, Siemer E, 1968. Effects of bulk density, aggregate size, and soil water suction on oxygen diffusion, redox potentials, and elongation of corn roots. Soil Science Society of America Journal. 32 (2): 180-186.

Gray M, Johnson M G, Dragila M, Kleber M, 2014. Water uptake in biochars: The roles of porosity and hydrophobicity. Biomass and Bioenergy, 61, 196-205.

Guedes Filho O, Blanco-Canqui H, Da Silva A, 2013. Least limiting water range of the soil seedbed for long-term tillage and cropping systems in the central Great Plains USA. Geoderma. 207: 99-110. 
Gugino B K, Abawi G S, Idowu O J, Schindelbeck R R, Smith L L, Thies J E, Wolfe D W, Van Es H M, 2009. Cornell soil health assessment training manual. Cornell University College of Agriculture and Life Sciences.

Hakansson I, 1990. A method for characterizing the state of compactness of the plough layer. Soil and Tillage Research. 16 (1-2): 105-120.

Hill R, 1990. Long-term conventional and no-tillage effects on selected soil physical properties. Soil Science Society of America Journal. 54 (1): 161-166.

Horn R, Domzzal H, Slowinska-Jurkiewicz A, Van Ouwerkerk C, 1995, Soil compaction processes and their effects on the structure of arable soils and the environment. Soil and Tillage Research, 35 (1-2), 23-36.

Horn R, 2004. Time dependence of soil mechanical properties and pore functions for arable soils. Soil Science Society of America Journal. 68 (4): 1131-1137.

Kay B, Silva Ad, Baldock J, 1997. Sensitivity of soil structure to changes in organic carbon content: predictions using pedotransfer functions. Canadian Journal of Soil Science. 77 (4): 655-667.

Kay B, Hajabbasi M, Ying J, Tollenaar M, 2006. Optimum versus non-limiting water contents for root growth, biomass accumulation, gas exchange and the rate of development of maize (Zea mays L.). Soil and Tillage Research. 88 (12): 42-54.

Kunz M, Gonçalves A D M d A, Reichert JM, Guimaraes R M L, Reinert D J, Rodrigues M F, 2013. Compactaçao do solo na integraçao soja-pecuaria de leite em Latossolo argiloso com semeadura direta e escarificaçao. Revista Brasileira de Ciencia do Solo. 37 (6): 1699-1708.

Lapen D, Topp G, Gregorich E, Curnoe W, 2004. Least limiting water range indicators of soil quality and corn production, eastern Ontario, Canada. Soil and Tillage Research. 78 (2): 151-170.

Letey J, 1958. Relationship between soil physical properties and crop production. In: Advances in soil science. Eds: Springer. pp. 277-294.

Lipiec J, Hatano R, 2003. Quantification of compaction effects on soil physical properties and crop growth. Geoderma. 116 (1-2), 107-136.

Lipiec J, Horn R, Pietrusiewicz J, Siczek A, 2012. Effects of soil compaction on root elongation and anatomy of different cereal plant species. Soil and Tillage Research. 121, 74-81.

Major J, Steiner C, Downie A, Lehmann J, Joseph S, 2009. Biochar effects on nutrient leaching. Biochar for environmental management: Science and technology. pp. 271.

McLean E, 1983. Soil pH and lime requirement. Methods of soil analysis: Part 2 Chemical and microbiological properties. 9: 199-224.

Mertoğlu S, 1982. Toprak Mekaniği Laboratuarı El Kitabı. TC Köyişleri ve Kooperatifler Bakanlığı. Topraksu Genel Müd. Yayın No: 713.

Reichert J M, Suzuki L E A S, Reinert D J, Horn R, Hakansson I, 2009. Reference bulk density and critical degree-ofcompactness for no-till crop production in subtropical highly weathered soils. Soil and Tillage Research. 102 (2): 242-254.

Safadoust A, Feizee P, Mahboubi A, Gharabaghi B, Mosaddeghi M, Ahrens B, 2014. Least limiting water range as affected by soil texture and cropping system. Agricultural Water Management. 136: 34-41.

Taylor H M, Roberson G M, Parker Jr J J, 1966. Soil strength-root penetration relations for medium-to coarse-textured soil materials. Soil science. 102 (1): 18-22.

Tormena C, Silva A d, Libardi P, 1998. Caracterização do intervalo hídrico ótimo de um Latossolo Roxo sob plantio direto, Revista Brasileira de Ciência do Solo. 22 (4): 573-581.

Tormena C A, da Silva A P, Libardi P L, 1999. Soil physical quality of a Brazilian Oxisol under two tillage systems using the least limiting water range approach. Soil and Tillage Research. 52 (3-4): 223-232.

Turgut B, Öztaş T, 2012. Penetrasyon direncini etkileyen bazı toprak özelliklerinin yersel değişiminin belirlenmesi. Journal of Agricultural Sciences. 18 (12).

Veihmeyer F, Hendrickson A, 1950. Soil moisture in relation to plant growth. Annual review of plant physiology. 1 (1): 285-304.

Vomocil J, Flocker W, 1961. Effect of soil compaction on storage and movement of soil air and water. Trans. Am. Soc. Agric. Eng.: 4.

Weber, K, Quicker, P, 2018. Properties of biochar. Fuel, pp. 240-261.

Wright A F, Bailey J S, 2001. Organic carbon, total carbon, and total nitrogen determinations in soils of variable calcium carbonate contents using a Leco CN-2000 dry combustion analyzer. Communications in Soil Science and Plant Analysis. 32 (19-20): 3243-3258.

Wu L, Feng G, Letey J, Ferguson L, Mitchell J, McCullough-Sanden B, Markegard G, 2003. Soil management effects on the nonlimiting water range. Geoderma. 114 (3-4): 401-414.

Yang C, D, Lu S, G, 2020. Effects of five different biochars on aggregation, water retention and mechanical properties of paddy soil: A field experiment of three-season crops. Soil and Tillage Research. 205, 104798.

Zou C, Sands R, Buchan G, Hudson I, 2000. Least limiting water range: a potential indicator of physical quality of forest soils. Soil Research. 38 (5): 947-958. 